\title{
Estimating pulmonary artery pressures by echocardiography in patients with
} emphysema

\author{
M.R. Fisher*, G.J. Criner" ${ }^{\#}$, A.P. Fishman ${ }^{\circ}$, P.M. Hassoun ${ }^{+}$, O.A. Minai ${ }^{\S}$, S.M. Scharf ${ }^{f}$ \\ and H.E. Fessler ${ }^{+}$for the National Emphysema Treatment Trial (NETT) Research \\ Group
}

ABSTRACT: In patients with emphysema being evaluated for lung volume reduction surgery, Doppler echocardiography has been used to screen for pulmonary hypertension as an indicator of increased peri-operative risk.

To determine the accuracy of this test, the present authors compared the results of right heart catheterisations and Doppler echocardiograms in 163 patients participating in the cardiovascular substudy of the National Emphysema Treatment Trial. Substudy patients had both catheterisation and Doppler echocardiography performed before and after randomisation.

In 74 paired catheterisations and echocardiograms carried out on 63 patients, the mean values of invasively measured pulmonary artery systolic pressures and the estimated right ventricular systolic pressures were similar. However, using the World Health Organization's definitions of pulmonary hypertension, echocardiography had a sensitivity of $60 \%$, specificity of $74 \%$, positive predictive value of $68 \%$ and a negative predictive value of $67 \%$ compared with the invasive measurement. Bland-Altman analysis revealed a bias of $0.37 \mathrm{kPa}$ with $95 \%$ limits of agreement from $-2.5-3.2 \mathrm{kPa}$.

In patients with severe emphysema, echocardiographic estimates of pulmonary artery pressures correlate very weakly with right heart catheterisations, and the test characteristics (e.g. sensitivity, specificity, etc.) of echocardiographic assessments are poor.

KEYWORDS: Echocardiography, emphysema, lung volume reduction surgery, pulmonary hypertension

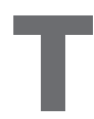
he presence of pulmonary hypertension $(\mathrm{PH})$ and cor pulmonale increases mortality and predicts hospital readmission for exacerbations in patients with chronic obstructive pulmonary disease (COPD) [1-3]. The need to identify $\mathrm{PH}$ in patients with COPD has taken on new significance due to two developments. First, the introduction of effective therapies for pulmonary arterial hypertension has renewed interest in treating other forms of $\mathrm{PH}$, such as that associated with COPD [4, 5]. Secondly, the introduction of lung volume reduction surgery (LVRS) for advanced emphysema increases the need for a practical test to diagnose $\mathrm{PH}$, which is a contraindication to LVRS [6].

The standard for measuring pulmonary pressures has been right heart catheterisation (RHC), but this test is invasive and costly. Transthoracic

STATEMENT OF INTEREST: None declared.

\section{AFFILIATIONS}

${ }^{*}$ Division of Pulmonary and Critical Care, Emory University, Atlanta, GA, "Division of Pulmonary and Critical Care, Temple University School of Medicine, and

-Division of Pulmonary and Critical Care, University of Pennsylvania,

Philadelphia, PA,

${ }^{+}$Division of Pulmonary and Critical Care, Johns Hopkins University, and ${ }^{f}$ Division of Pulmonary and Critical Care, University of Maryland, Baltimore, MD, and

${ }^{\S}$ Division of Pulmonary, Allergy, and Critical Care, Cleveland Clinic,

Cleveland, OH, USA.

CORRESPONDENCE

H.E. Fessler

1830 Monument St., 5th floor

Baltimore, MD 21287, USA

Fax: 14109550036

E-mail: hfessler@jhmi.edu

Received:

March 192007

Accepted after revision:

July 122007

SUPPORT STATEMENT

The National Emphysema Treatment

Trial (NETT) is supported by

contracts with the National Heart,

Lung, and Blood Institute

(N01HR76101, N01HR76102,

N01HR76103, N01HR76104,

N01HR76105, N01HR76106,

N01HR76107, N01HR76108,

N01HR76109, N01HR76110,

N01HR76111, N01HR76112,

N01HR76113, N01HR76114,

N01HR76115, N01HR76116,

N01HR76118 and N01HR76119),

the Centers for Medicare and

Medicaid Services (CMS; formerly

the Health Care Financing

Administration); and the Agency for

Healthcare Research and Quality

(AHRQ). patients with severe emphysema. Three of the 17 centres participated in a substudy designed to 
examine cardiovascular function in this patient population. In addition to the comprehensive battery of tests required for participation in the main NETT trial, including DE performed by standardised techniques, patients enrolled in the substudy also underwent RHC both before randomisation and at 6 months. This large population of patients with severe emphysema, having had both echocardiography and RHC within a short interval, offered a unique opportunity to further examine the accuracy of DE in estimating pulmonary pressures in patients with severe emphysema. Some of this data has been previously reported [10] and the baseline invasive pulmonary haemodynamics of a subset of these patients has been published [11].

\section{METHODS}

The institutional review boards for each participating NETT centre approved the protocols and all patients provided informed consent prior to enrolling in the study.

\section{Patient population}

The NETT methodology, and inclusion and exclusion criteria have been previously published [6]. Briefly, patients had advanced emphysema based on pulmonary function (forced expiratory volume in one second $(\mathrm{FEV} 1) \leqslant 45 \%$, total lung capacity $(\mathrm{TLC}) \geqslant 100 \%$, residual volume $(\mathrm{RV}) \geqslant 150 \%$ predicted ( $\%$ pred)) and computerised tomographic findings. Patients were excluded if they had medical comorbidities that excessively increased their surgical risk, decreased their expected functional benefit, or decreased the likelihood that they would provide follow-up data. Evaluation included arterial blood gases at rest while breathing room air and pulse oximetry while walking. Domiciliary oxygen was prescribed for hypoxic patients in accordance with the Centers for Medicare and Medicaid Services guidelines [12]. All patients underwent $6-10$ weeks of pulmonary rehabilitation prior to randomisation.

All patients screened for the NETT at the substudy centres were asked to participate in the cardiovascular substudy during their baseline evaluation. All cardiovascular substudy subjects were included in this analysis, even if they subsequently failed to meet all NETT criteria for randomisation. Of the substudy subjects, $67 \%$ met randomisation criteria. The most common reasons for exclusion from randomisation were as follows: not meeting pulmonary function or computed tomography criteria; cardiac disease including pulmonary hypertension; and physician judgment.

\section{Echocardiograms}

Resting two-dimensional DE were performed using standard techniques. Studies were interpreted by staff cardiologists at each centre. In studies technically adequate for interpretation, the transtricuspid pressure gradient was calculated using the modified Bernoulli equation $\left(4 v^{2}\right)$ where $v$ is the maximum velocity of the tricuspid valve regurgitant jet. Right atrial pressure (RAP) was estimated by the respiratory variation in the diameter of the inferior vena cava and was categorised as 5 , 10 or $15 \mathrm{mmHg}$. Right ventricular systolic pressure (RVSP) was calculated by adding the transtricuspid pressure gradient to the RAP estimate.

\section{Right heart catheterisations}

RHC was performed with supplemental oxygen to maintain arterial oxygen saturation $>90 \%$. All haemodynamic measurements are reported as the mean of three measurements at endexpiration. Mean pulmonary artery pressure $\left(\bar{P}_{\mathrm{pa}}\right)$ was calculated as the pulmonary artery diastolic pressure plus one-third of the pulse pressure. Thermodilution cardiac output is reported as the mean of at least five injections in which agreement was within $20 \%$.

\section{Statistical methods}

The DE estimates of RVSP and the RHC pulmonary artery systolic pressures (Ppas) were compared by correlation and Bland-Altman analysis [11, 13]. The present authors report bias and the $95 \%$ limits of agreement, calculated as the bias \pm 1.96 times the SD of the differences. Clinically acceptable accuracy was operationally defined as an RVSP within $1.33 \mathrm{kPa}$ of the Ppas measurement.

Sensitivity, specificity, and positive and negative predictive values were calculated using the World Health Organization (WHO) criteria for $\mathrm{PH}\left(\bar{P}_{\text {pa }}\right.$ during $\mathrm{RHC}>3.3 \mathrm{kPa}$, or RVSP $\geqslant 5.3 \mathrm{kPa}$ on DE) [14].

The individual differences between DE and RHC measurements were correlated against body mass index (BMI), FEV1 \% pred, a global severity of emphysema score based on high resolution computed tomography findings, and the RV/TLC ratio.

\section{RESULTS}

The cardiovascular substudy enrolled 163 patients from the NETT, including those who had been screened but not found eligible for randomisation. The relationship between these patients and the rest of the 3,777 patients screened at the 17 NETT centres is shown in figure 1. Subject demographics, pulmonary function tests and arterial blood gas results at the initial screening visit are shown in table 1 , with mean values for the substudy subjects compared with the total 1,218 patients randomised in the NETT. Compared with the NETT population, patients in the substudy had slightly higher FEV1/ forced vital capacity, smaller TLC, and included more AfricanAmericans.

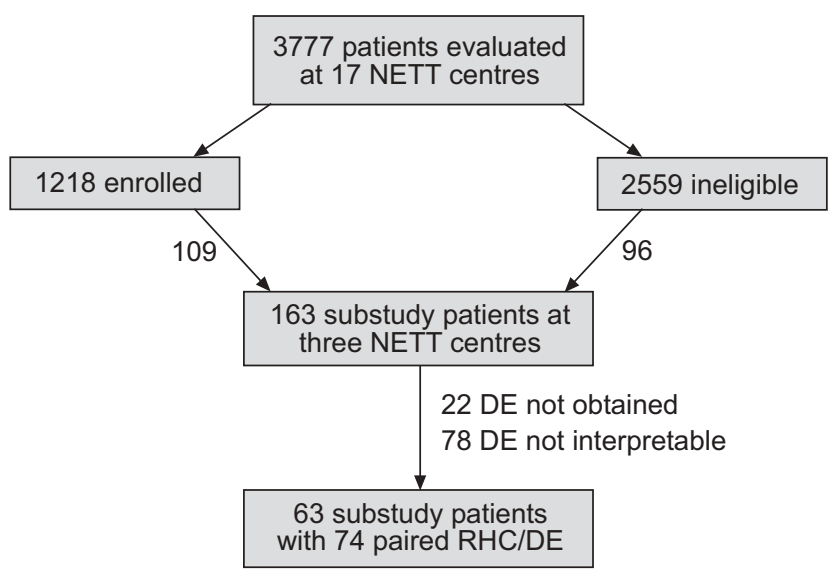

FIGURE 1. Patient flow diagram. NETT: National Emphysema Treatment Trial; DE: Doppler echocardiography; RHC: right heart catheterisation. 


\begin{tabular}{|c|c|c|}
\hline & CV substudy & NETT \\
\hline \multicolumn{3}{|l|}{ Demographics } \\
\hline Patients n & 163 & 1218 \\
\hline Age yrs & $65.6 \pm 6.6$ & $66.4 \pm 6.1$ \\
\hline Male \% & 60.1 & 61.2 \\
\hline \multicolumn{3}{|l|}{ Race \% } \\
\hline C/AA/O & 89.6/9.8/0.6 & $94.9 / 3.4 / 1.6$ \\
\hline \multicolumn{3}{|c|}{ Pulmonary function } \\
\hline FEV $1 / F V C$ & $32.9 \pm 7.2$ & $31.6 \pm 6.4$ \\
\hline FEV1 $\%$ pred & $27.2 \pm 7.2$ & $26.9 \pm 7.1$ \\
\hline FVC \% pred & $65.5 \pm 15.6$ & $66.8 \pm 15.2$ \\
\hline TLC \% pred & $125.2 \pm 14.5$ & $129.0 \pm 14.5$ \\
\hline RV \% pred & $223.2 \pm 47.9$ & $225.4 \pm 48.0$ \\
\hline DL,CO \% pred & $27.0 \pm 9.3$ & $28.3 \pm 9.7$ \\
\hline \multicolumn{3}{|c|}{ Arterial blood gas } \\
\hline $\mathrm{pH}$ & $7.42 \pm 0.03$ & $7.42 \pm 0.03$ \\
\hline${\mathrm{Pa}, \mathrm{CO}_{2} \mathrm{mmHg}}$ & $42.8 \pm 6.3$ & $42.8 \pm 5.3$ \\
\hline${\mathrm{Pa}, \mathrm{O}_{2}}_{\mathrm{mmHg}}$ & $65.2 \pm 10.3$ & $64.6 \pm 10.2$ \\
\hline
\end{tabular}

Data are presented as mean for continuous variables $\pm \mathrm{SD}$, unless otherwise indicated. CV: cardiovascular; NETT: National Emphysema Treatment Trial; C: Caucasian; AA: African-American; O: other; FEV1: forced expiratory volume in one second; FVC: forced vital capacity; \% pred: \% predicted; TLC: total lung capacity; RV: residual volume; DL,CO: diffusing capacity of the lung for carbon monoxide; $\mathrm{Pa}_{1} \mathrm{CO}_{2}$ : carbon dioxide arterial tension; $\mathrm{Pa}_{\mathrm{a}} \mathrm{O}_{2}$ : arterial oxygen tension. $1 \mathrm{mmHg}=0.133 \mathrm{kPa}$.

Results from the pre-randomisation baseline RHC are shown in table 2 . The average $\bar{P}_{\text {pa }}$ was $3.2 \mathrm{kPa}$ (SD 0.8 ). In total, $37 \%$ of patients met WHO criteria for $\mathrm{PH}\left(\bar{P}_{\mathrm{pa}}>3.33 \mathrm{kPa}\right)$. Of those, $48 \%$ had pulmonary capillary wedge pressures $<2.1 \mathrm{kPa}$, suggesting that their elevated pressure was not due to left heart disease. Nine $(6 \%)$ out of the 163 patients met criteria for moderate PH $\left(\bar{P}_{\text {pa }}>4.66 \mathrm{kPa}\right)$ and one $(0.6 \%)$ out of $163 \mathrm{had}$ severe $\mathrm{PH}\left(\bar{P}_{\mathrm{pa}}>6.0 \mathrm{kPa}\right)$.

Table 3 shows results from the pre-randomisation baseline DE. Results of DE were not available for 22 patients who were found to be ineligible by other NETT exclusion criteria prior to obtaining their DE. RVSP estimates could be recorded in only $37.6 \%$ of 141 patients on their baseline DE. The median time between the DE and RHC was 23 days.
In 74 paired RHCs and DEs carried out on 63 patients, the mean values of invasively measured $P$ pas and the estimated RVSP were similar $(4.9 \pm 0.9$ versus $5.2 \pm 1.3 \mathrm{kPa})$. However, the Bland-Altman plot of the $P$ pas (fig. 2) reveals substantial imprecision. The bias was $0.37 \mathrm{kPa}$ for the difference between the DE and RHC pressures and the $95 \%$ limits of agreement were $-1.2-3.2 \mathrm{kPa}$. Furthermore, there was only very weak correlation between the pressures as measured by RHC and DE (fig. 3). Using an assumed RAP of $1.33 \mathrm{kPa}$ instead of the estimated pressure, the bias was $0.55 \mathrm{kPa}$ and the $95 \%$ limits of agreement were -2.3 and $3.4 \mathrm{kPa}$, respectively.

Echocardiography was inaccurate by $>1.33 \mathrm{kPa}$ in about onethird of patients (fig. 4). There was also wide variability in the RAP estimates (fig. 5), as demonstrated by the range of the RHC RAP measurement for each of the three possible DE estimates. However, using an assumed RAP of $1.33 \mathrm{kPa}$ did not improve the accuracy of the DE estimate of RVSP (31\% of estimates differed from $P$ pas by $>1.33 \mathrm{kPa}$ ). Furthermore, using the actual RAP measurement from RHC to calculate the DE RVSP actually made the accuracy worse (35\% of estimates differed from $P$ pas by $>1.33 \mathrm{kPa})$. This suggests that the error in RAP estimation was not the major source of error in the RVSP estimate.

Using WHO criteria for PH from RHC ( $\left.\bar{P}_{\text {pa }}>3.3 \mathrm{kPa}\right)$ and DE (RVSP $\geqslant 5.3 \mathrm{kPa}$ ), sensitivity, specificity, and positive and negative predictive values were calculated for DE. Transthoracic DE had a sensitivity of $60 \%$ (95\% confidence intervals (CI) $42-76 \%$ ), a specificity of $74 \%$ (95\% CI $58-87 \%$ ), a positive predictive value of $68 \%$ (95\% CI $49-83 \%)$ and a negative predictive value of $67 \%$ (95\% CI 51-81\%) compared with RHC.

The present authors sought to determine if characteristics of body habits, hyperinflation or emphysema severity influenced the accuracy of DE by correlating BMI, RV/TLC, percentage predicted FEV1, and global emphysema severity on computed tomography scan against the difference between RVSP and $P$ pas. There was no correlation between any of the patient characteristics and the measurement difference. Limiting the Bland-Altman analysis to patients who had upper lobe predominant emphysema also did not improve the accuracy of DE.

\section{DISCUSSION}

RHC has long been considered the gold standard for diagnosing PH. Current recommendations for the evaluation

TABLE 2 Baseline right heart catheterisation results

\begin{tabular}{lcccc} 
& $\mathbf{n}$ & Mean & SD & Minimum-maximum \\
\hline Right atrial pressure $\mathbf{m m H g}$ & 163 & 7.9 & 4.0 & $1-24$ \\
Pulmonary artery systolic pressure $\mathbf{m m H g}$ & 162 & 35.7 & 7.8 & $14-66$ \\
Pulmonary artery diastolic pressure $\mathbf{m m H g}$ & 162 & 18.1 & 6.0 & $2-38$ \\
Mean pulmonary artery pressure $\mathbf{m m H g}$ & 163 & 24.0 & 6.2 & $11-47$ \\
Pulmonary capillary wedge pressure $\mathbf{m m H g}$ & 163 & 12.8 & 4.9 & $2-28$ \\
Cardiac output L. $\mathbf{m i n}^{-\mathbf{1}}$ & 160 & 5.1 & 1.1 & $2.3-9.1$ \\
\hline
\end{tabular}




\begin{tabular}{|c|c|c|c|c|c|}
\hline \multirow[t]{2}{*}{ TABLE 3} & \multicolumn{5}{|c|}{$\begin{array}{l}\text { Pre-randomisation baseline Doppler } \\
\text { echocardiography findings for patients with an } \\
\text { interpretable study }\end{array}$} \\
\hline & & n & Mean & SD & $\begin{array}{l}\text { Minimum- } \\
\text { maximum }\end{array}$ \\
\hline \multicolumn{2}{|c|}{ Right atrial pressure $\mathrm{mmHg}$} & 58 & 8.4 & 2.4 & $5-10$ \\
\hline \multicolumn{2}{|c|}{$\begin{array}{l}\text { Peak tricuspid regurgitant } \\
\text { velocity } \mathrm{m} \cdot \mathrm{s}^{-1}\end{array}$} & 53 & 2.75 & 0.4 & $2-3.8$ \\
\hline \multicolumn{2}{|c|}{$\begin{array}{l}\text { Right ventricular systolic } \\
\text { pressure } \mathrm{mmHg}\end{array}$} & 53 & 39.3 & 9.4 & $24-68$ \\
\hline
\end{tabular}

of patients with suspected $\mathrm{PH}$ begin with an echocardiogram to estimate the RVSP and to evaluate for right heart chamber enlargement [15]. This is supported by multiple previous studies showing a good correlation between DE measurements and RHC $[7,8]$. However, these studies have been performed largely in patients with diseases other than emphysema, in whom DE estimates of peak tricuspid regurgitant velocity may not be as technically challenging. These studies have included patients with a variety of pulmonary and vascular disorders, but with such a wide range of pulmonary artery pressures that statistically significant correlations were found despite rather large variance. The current study is one of the few limited to patients with severe, well-characterised emphysema that has compared these two diagnostic modalities.

The accuracy of DE for the assessment of right-sided pressures in patients with lung disease has been questioned previously. ARCASOY et al. [16] reported 166 patients with a variety of lung diseases being evaluated for lung transplantation at a single centre. As in the current study, ARCASOY et al. [16] defined DE

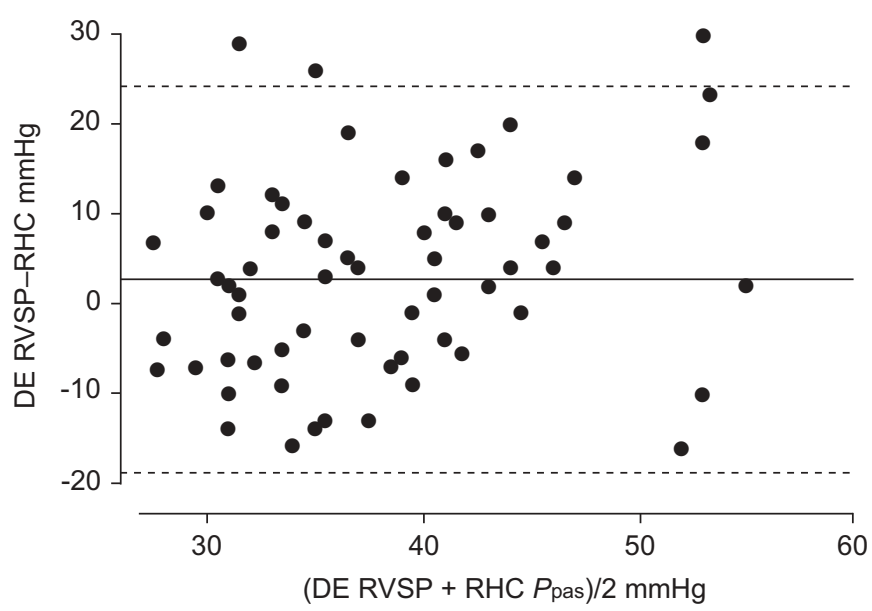

FIGURE 2. Bland-Altman plot of pulmonary artery systolic pressure (Ppas). The abscissa is the average of the Doppler echocardiogram (DE) estimate and the right heart catheterisation $(\mathrm{RHC})$ measurement of the $P$ pas and the ordinate axis is difference between the two measurements for each paired observation. $D E$, on average, overestimates the measured $P$ pas (bias $=2.81 \mathrm{mmHg} ;-$ ). RVSP: right ventricular systolic pressure. The $95 \%$ limits of agreement (-----) were -18.7 and $24.3 \mathrm{mmHg} . \mathrm{n}=74$ paired measurements on 63 patients. $1 \mathrm{mmHg}=0.133 \mathrm{kPa}$.

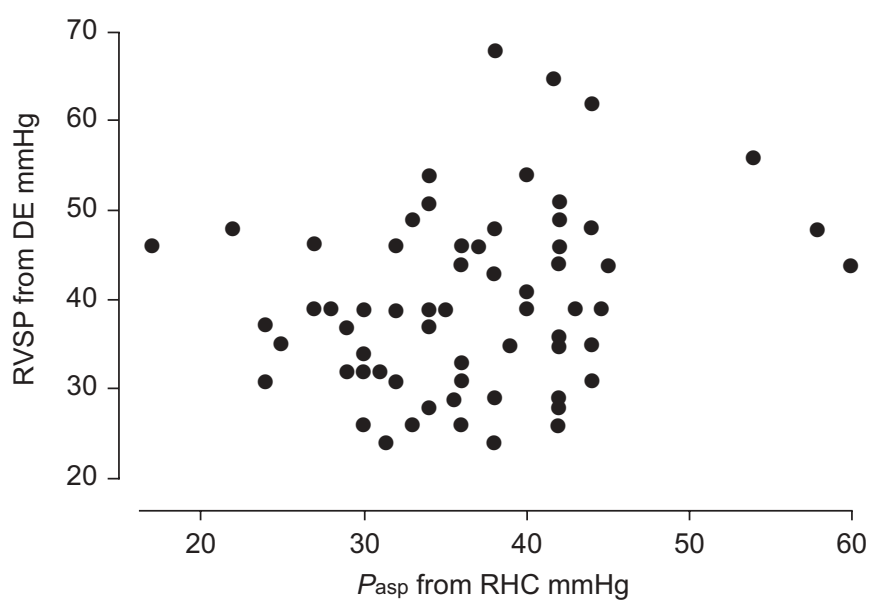

FIGURE 3. Scatter-plot between Doppler echocardiography (DE) estimate of right ventricular systolic pressure (RVSP) and pulmonary artery systolic pressure (Ppas) measured at right heart catheterisation $(\mathrm{RHC})$. Pearson's correlation $=0.23$ (95\% confidence interval 0.001-0.44). $n=74$ paired measurements on 63 patients. $1 \mathrm{mmHg}=0.133 \mathrm{kPa}$.

as "accurate" if the RVSP estimate was within $\pm 1.3 \mathrm{kPa}$ of the $P$ pas on RHC. Among the patients with obstructive lung disease, RVSP could be estimated in only $38 \%$ of patients, or 96 patients. It was inaccurate $44 \%$ of the time, with a sensitivity of $76 \%$ and specificity of $65 \%$. Signs of RV dysfunction on echocardiogram did not improve the accuracy of DE. Another study that compared RHC with DE measures of RVSP in 25 patients being evaluated for LVRS also found poor correlation between the measures [17]. Despite the differences in patient populations and methodology, these findings are quite similar to the present findings and support the present conclusion that $\mathrm{DE}$ is an inappropriate screening tool for pulmonary hypertension in patients with severe emphysema.

Two other studies have been less critical of DE, and it is possible that it performs better in patients who are less hyperinflated than the NETT subjects. LAABAN et al. [18] were

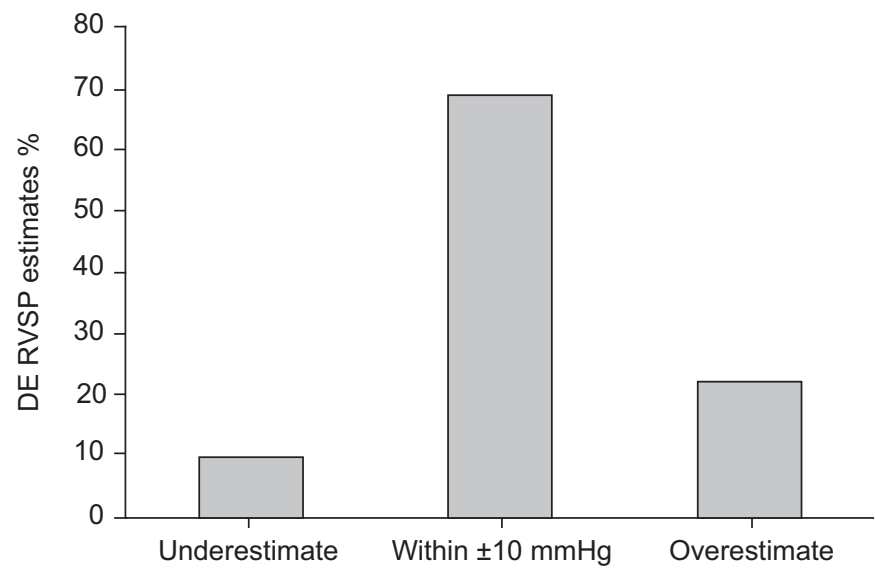

FIGURE 4. Percentage of Doppler echocardiography (DE) estimates of right ventricular systolic pressure (RVSP) within $10 \mathrm{mmHg}$ of the measured pulmonary artery systolic pressure at right heart catheterisation. $\mathrm{n}=74$ paired measurements on 63 patients. $1 \mathrm{mmHg}=0.133 \mathrm{kPa}$. 
able to obtain DE estimates of RVSP in $66 \%$ of 41 patients with COPD, and found a statistically significant correlation with invasive systolic pulmonary artery pressure. However, these patients were substantially less hyperinflated than the patients in the current paper (RV 143 versus $223 \%$ pred, TLC 99 versus $125 \%$ pred). TRAMARIN et al. [9] also found a statistically significant correlation between these measures in $30 \mathrm{COPD}$ patients whose lung function is not described. However, in both these studies, the two measures differed from each other by $>1.33 \mathrm{kPa}$ in about one-third of subjects, and one-quarter or more would have been misclassified as to the presence of $\mathrm{PH}$ based on RVSP. This illustrates that a significant correlation to an accurate measurement does not imply that the correlate is also accurate [13].

Positive and negative predictive values of a diagnostic test, such as DE, will be dependent upon the disease prevalence in the population. The present authors' estimates for the prevalence of $\mathrm{PH}$ in patients with severe emphysema may not indicate its true prevalence, since patients evaluated for the NETT are a highly select subset of patients with emphysema. Many with previously known PH may not have been referred for initial screening in the NETT and thus not included in this substudy. Patients with severe hypoxia, poor functional capacity, left heart failure, or other conditions associated with $\mathrm{PH}$ in addition to emphysema would also have been excluded from study or never referred. Alternatively, patients with dyspnoea as a result of their secondary $\mathrm{PH}$ may have been more likely to seek participation in the NETT. Although the positive and negative predictive values of DE may vary in other groups of emphysema patients, any test used for screening purposes should have a high sensitivity.

Right ventricular systolic pressure is estimated with DE by aligning the Doppler probe parallel to the axis of the regurgitant jet across the tricuspid value. The regurgitant flow signal is imaged, peak flow velocity is measured, and the transvalvular gradient calculated using the modified Bernoulli equation [7]. This is added to RAP, which is either assumed to be the same in all patients or estimated from the height of jugular vein distension or from the degree of inspiratory collapse of the inferior vena cava.

There are two reasons why these theoretically sound techniques may fail in patients with emphysema: 1) difficulty in visualising the heart and in aligning the probe because of the heart's narrow, vertical orientation; and 2) difficulty in obtaining a clear signal of regurgitant flow because hyperinflation increases the distance between the probe and degrades the image. These technical difficulties are likely to explain why interpretable signals could not be obtained at all in the majority of patients. It is a reasonable speculation that the signals, though measurable, were of suboptimal quality in many of the remaining patients. The use of contrast (i.e. agitated saline) has been shown to increase the ability to estimate RVSP [19-21]; however, it is unclear if this improves its accuracy.

Limitations of this study arise from the original design of the cardiovascular substudy, which was not specifically designed to examine the accuracy of DE. The DE were not performed immediately before or after RHC, so the possibility that the patient's pulmonary artery pressure had changed in the

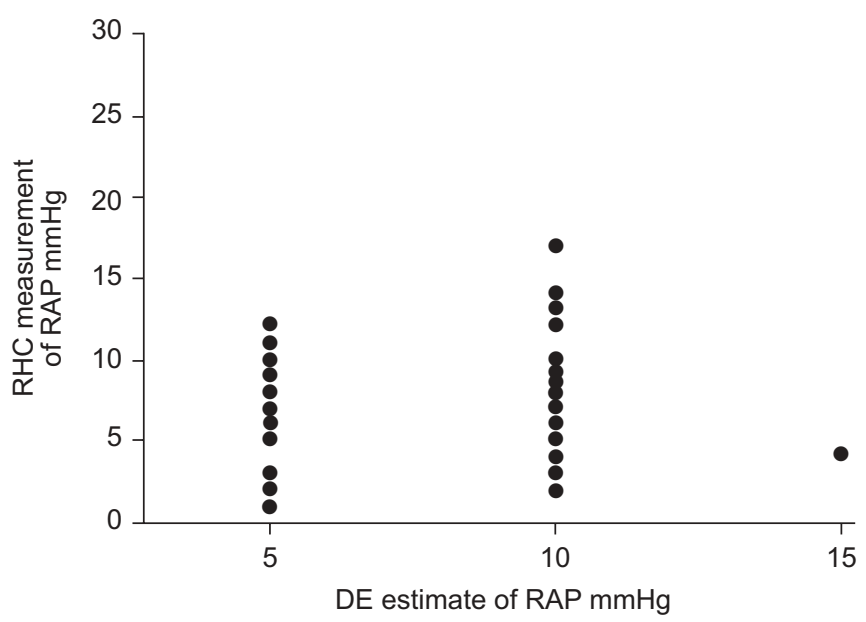

FIGURE 5. Right atrial pressure (RAP) from echocardiography and catheterisation. Doppler echocardiography (DE) estimate of RAP compared with the measured RAP at right heart catheterisation $(\mathrm{RHC}) . \mathrm{n}=74$ paired measurements on 63 patients. $1 \mathrm{mmHg}=0.133 \mathrm{kPa}$.

interval can not be excluded. However, limiting the analysis to studies that were carried out within 14 days of each other failed to improve agreement between DE and RHC measurements. Furthermore, a long-term study of pulmonary arterial haemodynamics in patients with COPD with $\leqslant 6$ yrs of followup showed changes smaller than the differences seen using the two techniques in the present study [2]. Thus, it is unlikely that the discrepancies between methods are due to biological changes in the patients between testing.

The present study is also limited by the data recorded on case report forms for the NETT cardiovascular substudy. The reason why a study was technically inadequate was not recorded. Measures of right ventricular function, dimensions, or wall thickness were also not recorded. These variables are available to the clinical echocardiographer and can influence their interpretation of the presence or absence of $\mathrm{PH}$. The present study design does not make it possible to determine if those factors would increase the diagnostic accuracy of DE. Earlier studies have suggested that the absence of right-sided chamber enlargement has a high negative predictive value [16, 17].

Patients were all on oxygen during their RHC, whereas they only used oxygen during DE if it had been prescribed. However, all patients who were hypoxic at rest were prescribed oxygen. If the administration of supplemental oxygen during RHC had caused pulmonary vasodilation, systematic underestimation of RHC pressures compared with DE would have resulted. Although the bias was in that direction, its value was close to zero and DE underestimated the pressure almost as frequently as it overestimated it.

Echocardiography was performed at each clinical centre according to specifications in the NETT manual of procedures. However, technicians were not specially trained in image acquisition for the NETT, equipment was not uniform, and studies were interpreted on-site by local cardiologists. This may have introduced some error, compared with using a highly standardised technique with a few, specially trained 
technicians and cardiologists or centralised image interpretation and discrepancy resolution. While this may lead to an underestimation of the potential accuracy of $\mathrm{DE}$, it is much more representative of how echocardiography is performed in general practice. Thus, these findings may be more readily generalised to the community and, unfortunately, cast doubt on the utility of this widely used test in patients with emphysema.

The findings of the present study also raise concerns about the use of DE in the main NETT study and its use in the community to screen patients prior to LVRS. The present findings would suggest that an unknown number of patients with exclusionary pulmonary hypertension were nevertheless enrolled in the NETT and randomised to surgery. Similarly, an unknown number of qualified subjects may have been excluded based on DE measures that were in error. The NETT outcomes remain valid when applied to patients screened by the same techniques. However, caution is advised when excluding patients for LVRS based only on an elevated RVSP measurement, and suggest that the absence of $\mathrm{PH}$ in eligible patients be confirmed by RHC prior to surgery.

In conclusion, the present study has found that Doppler echocardiography is frequently inaccurate in patients with severe emphysema. The test characteristics (sensitivity, specificity and predictive values) are poor for the ability of Doppler echocardiography to detect pulmonary hypertension. As detecting pulmonary hypertension in the current patient population can have important diagnostic, prognostic and therapeutic implications, physicians should interpret results of Doppler echocardiography cautiously and consider confirming these estimates with right heart catheterisation after taking into account the risks of this more invasive procedure.

\section{ACKNOWLEDGEMENTS}

\section{MEMBERS OF THE NETT RESEARCH GROUP}

Office of the Chair of the Steering Committee, University of Pennsylvania, Philadelphia, PA, USA: A. P. Fishman (Chair); B. A. Bozzarello; A. Al-Amin.

\section{Clinical centres}

Baylor College of Medicine, Houston, TX, USA: M. Katz (Principal Investigator); C. Wheeler (Principal Clinic Coordinator); E. Baker; P. Barnard; P. Cagle; J. Carter; S. Chatziioannou; K. Conejo-Gonzales; K. Dubose; J. Haddad; D. Hicks; N. Kleiman; M. Milburn-Barnes; C. Nguyen; M. Reardon; J. Reeves-Viets; S. Sax; A. Sharafkhaneh; O. Wilson; C. Young; R. Espada (Principal Investigator 1996-2002); R. Butanda (1999-2001); M. Ellisor (2002); P. Fox (1999-2001); K. Hale (1998-2000); E. Hood (1998-2000); A. Jahn (1998-2000); S. Jhingran (1998-2001); K. King (1998-1999); C. Miller III (19961999); I. Nizami (Co-Principal Investigator, 2000-2001); T. Officer (1998-2000); J. Ricketts (1998-2000); J. Rodarte (CoPrincipal Investigator 1996-2000); R. Teague (Co-Principal Investigator 1999-2000); K. Williams (1998-1999).

Brigham and Women's Hospital, Boston, MA, USA: J. Reilly (Principal Investigator); D. Sugarbaker (Co-Principal Investigator); C. Fanning (Principal Clinic Coordinator); S. Body; S. Duffy; V. Formanek; A. Fuhlbrigge; P. Hartigan;
S. Hooper; A. Hunsaker; F. Jacobson; M. Moy; S. Peterson; R. Russell; D. Saunders; S. Swanson (Co-Principal Investigator, 1996-2001).

Cedars-Sinai Medical Center, Los Angeles, CA, USA: R. McKenna (Principal Investigator); Z. Mohsenifar (CoPrincipal Investigator); C. Geaga (Principal Clinic Coordinator); M. Biring; S. Clark; J. Cutler; R. Frantz; P. Julien; M. Lewis; J. Minkoff-Rau; V. Yegyan; M. Joyner (19962002).

Cleveland Clinic Foundation, Cleveland, OH, USA: M. DeCamp (Principal Investigator); J. Stoller (Co-Principal Investigator); Y. Meli (Principal Clinic Coordinator); J. Apostolakis; D. Atwell; J. Chapman; P. DeVilliers; R. Dweik; E. Kraenzler; R. Lann; N. Kurokawa; S. Marlow; K. McCarthy; P. McCreight; A. Mehta; M. Meziane; O. Minai; M. Steiger; K. White; J. Maurer (Principal Investigator, 1996-2001); T. Durr (2000-2001); C. Hearn (1998-2001); S. Lubell (1999-2000); P. O’Donovan (1998-2003); R. Schilz (1998-2002).

Columbia University, New York, NY, in consortium with Long Island Jewish (LIJ) Medical Center, New Hyde Park, NY, USA: M. Ginsburg (Principal Investigator); B. Thomashow (CoPrincipal Investigator); P. Jellen (Principal Clinic Coordinator); J. Austin; M. Bartels; Y. Berkmen; P. Berkoski (Site Coordinator, LIJ); F. Brogan; A. Chong; G. DeMercado; A. DiMango; S. Do; B. Kachulis; A. Khan; B. Mets; M. O'Shea; G. Pearson; L. Rossoff; S. Scharf (Co-Principal Investigator, 19982002); M. Shiau; P. Simonelli; K. Stavrolakes; D. Tsang; D. Vilotijevic; C. Yip; M. Mantinaos (1998-2001); K. McKeon (1998-1999); J. Pfeffer (1997-2002).

Duke University Medical Center, Durham, NC, USA: N. MacIntyre (Principal Investigator); R.D. Davis (Co-Principal Investigator); J. Howe (Principal Clinic Coordinator); R.E. Coleman; R. Crouch; D. Greene; K. Grichnik; D. Harpole Jr; A. Krichman; B. Lawlor; H. McAdams; J. Plankeel; S. RinaldoGallo; S. Shearer; J. Smith; M. Stafford-Smith; V. Tapson; M. Steele (1998-1999); J. Norten (1998-1999).

Mayo Foundation, Rochester, MN, USA: J. Utz (Principal Investigator); C. Deschamps (Co-Principal Investigator); K. Mieras (Principal Clinic Coordinator); M. Abel; M. Allen; D. Andrist; G. Aughenbaugh; S. Bendel; E. Edell; M. Edgar; B. Edwards; B. Elliot; J. Garrett; D. Gillespie; J. Gurney; B. Hammel; K. Hanson; L. Hanson; G. Harms; J. Hart; T. Hartman; R. Hyatt; E. Jensen; N. Jenson; S. Kalra; P. Karsell; J. Lamb; D. Midthun; C. Mottram; S. Swensen; A-M. Sykes; K. Taylor; N. Torres; R. Hubmayr (1998-2000); D. Miller (1999_ 2002); S. Bartling (1998-2000); K. Bradt (1998-2002).

National Jewish Medical and Research Center, Denver, CO, USA: B. Make (Principal Investigator); M. Pomerantz (CoPrincipal Investigator); M. Gilmartin (Principal Clinic Coordinator); J. Canterbury; M. Carlos; P. Dibbern; E. Fernandez; L. Geyman; C. Hudson; D. Lynch; J. Newell; R. Quaife; J. Propst; C. Raymond; J. Whalen-Price; K. Winner; M. Zamora; R. Cherniack (Principal Investigator, 1997-2000).

Ohio State University, Columbus, OH, USA: P. Diaz (Principal Investigator); P. Ross (Co-Principal Investigator); T.Bees (Principal Clinic Coordinator); J. Drake; C. Emery; M. Gerhardt; M. King; D. Rittinger; M. Rittinger. 
Saint Louis University, Saint Louis, MO, USA: K. Naunheim (Principal Investigator); R. Gerber (Co-Principal Investigator); J. Osterloh (Principal Clinic Coordinator); S. Borosh; W. Chamberlain; S. Frese; A. Hibbit; M.E. Kleinhenz; G. Ruppel; C. Stolar; J. Willey; F. Alvarez (Co-Principal Investigator, 19992002); C. Keller (Co-Principal Investigator, 1996-2000).

Temple University, Philadelphia, PA, USA: G. Criner (Principal Investigator); S. Furukawa (Co-Principal Investigator); A.M. Kuzma (Principal Clinic Coordinator); R. Barnette; N. Brister; K. Carney; W. Chatila; F. Cordova; G. D'Alonzo; M. Keresztury; K. Kirsch; C. Kwak; K. Lautensack; M. Lorenzon; U. Martin; P. Rising; S. Schartel; J. Travaline; G. Vance; P. Boiselle (1997-2000); G. O'Brien (1997-2000).

University of California, San Diego, San Diego, CA, USA: A. Ries (Principal Investigator); R. Kaplan (Co-Principal Investigator); C. Ramirez (Principal Clinic Coordinator); D. Frankville; P. Friedman; J. Harrell; J. Johnson; D. Kapelanski; D. Kupferberg; C. Larsen; T. Limberg; M. Magliocca; F.J. Papatheofanis; D. Sassi-Dambron; M. Weeks.

University of Maryland at Baltimore, Baltimore, MD, in consortium with Johns Hopkins Hospital, Baltimore, MD, USA: M. Krasna (Principal Investigator); H. Fessler (CoPrincipal Investigator); I. Moskowitz (Principal Clinic Coordinator); T. Gilbert; J. Orens; S. Scharf; D. Shade; S. Siegelman; K. Silver; C. Weir; C. White.

University of Michigan, Ann Arbor, MI, USA: F. Martinez (Principal Investigator); M. Iannettoni (Co-Principal Investigator); C. Meldrum (Principal Clinic Coordinator); W. Bria; K. Campbell; P. Christensen; K. Flaherty; S. Gay; P. Gill; P. Kazanjian; E. Kazerooni; V. Knieper; T. Ojo; L. Poole; L. Quint; P. Rysso; T. Sisson; M. True; B. Woodcock; L. Zaremba.

University of Pennsylvania, Philadelphia, PA, USA: L. Kaiser (Principal Investigator); J. Hansen-Flaschen (Co-Principal Investigator); M.L. Dempsey (Principal Clinic Coordinator); A. Alavi; T. Alcorn, S. Arcasoy; J. Aronchick; S. Aukberg; B. Benedict; S. Craemer; R. Daniele; J. Edelman; W. Gefter; L. Kotler-Klein; R. Kotloff; D. Lipson; W. Miller Jr; R. O'Connell; S. Opelman; H. Palevsky; W. Russell; H. Sheaffer; R. Simcox; S. Snedeker; J. Stone-Wynne; G. Tino; P. Wahl; J. Walter; P. Ward; D. Zisman; J. Mendez (1997-2001); A. Wurster (1997-1999).

University of Pittsburgh, Pittsburgh, PA, USA: F. Sciurba (Principal Investigator); J. Luketich (Co-Principal Investigator); C. Witt (Principal Clinic Coordinator); G. Ayres; M. Donahoe; C. Fuhrman; R. Hoffman; J. Lacomis; J. Sexton; W. Slivka; D. Strollo; E. Sullivan; T. Simon; C. Wrona; G. Bauldoff (19972000); M. Brown (1997-2002); E. George (Principal Clinic Coordinator 1997-2001); R. Keenan (Co-Principal Investigator 1997-2000); T. Kopp (1997-1999); L. Silfies (1997-2001).

University of Washington, Seattle, WA, USA: J. Benditt (Principal Investigator), D. Wood, MD (Co-Principal Investigator); M. Snyder (Principal Clinic Coordinator); K. Anable; N. Battaglia; L. Boitano; A. Bowdle; L. Chan; C. Chwalik; B. Culver; T. Gillespy; D. Godwin; J. Hoffman; A. Ibrahim; D. Lockhart; S. Marglin; K. Martay; P. McDowell; D. Oxorn; L. Roessler; M. Toshima; S. Golden (1998-2000).

\section{OTHER PARTICIPANTS}

Agency for Healthcare Research and Quality, Rockville, MD, USA: L. Bosco; Y-P. Chiang; C. Clancy; H. Handelsman.

Centers for Medicare and Medicaid Services, Baltimore, MD, USA: S.M. Berkowitz; T. Carino; J. Chin; J. Baldwin; K. McVearry; A. Norris; S. Shirey; C. Sikora; S. Sheingold (19972004).

Coordinating Center, The Johns Hopkins University, Baltimore, MD, USA: S. Piantadosi (Principal Investigator); J. Tonascia (Co-Principal Investigator); P. Belt; A. Blackford; K. Collins; B. Collison; R. Colvin; J. Dodge; M. Donithan; V. Edmonds; G.L. Foster; J. Fuller; J. Harle; R. Jackson; S. Lee; C. Levine; H. Livingston; J. Meinert; J. Meyers; D. Nowakowski; K. Owens; S. Qi; M. Smith; B. Simon; P. Smith; A. Sternberg; M. Van Natta; L. Wilson; R. Wise.

Cost Effectiveness Subcommittee: R.M. Kaplan (Chair); J. Sanford Schwartz (Co-Chair); Y-P. Chiang; M.C. Fahs; A.M. Fendrick; A.J. Moskowitz; D. Pathak; S. Ramsey; S. Sheingold; A.L. Shroyer; J. Wagner; R. Yusen.

Cost Effectiveness Data Center, Fred Hutchinson Cancer Research Center, Seattle, WA, USA: S. Ramsey (Principal Investigator); R Etzioni; S. Sullivan; D. Wood; T. Schroeder; K. Kreizenbeck; K. Berry; N. Howlader.

CT Scan Image Storage and Analysis Center, University of Iowa, Iowa City, IA, USA: E. Hoffman (Principal Investigator); J. Cook-Granroth; A. Delsing; J. Guo; G. McLennan; B. Mullan; C. Piker; J. Reinhardt; B. Robinswood; J. Sieren; W. Stanford.

Data and Safety Monitoring Board: J.A. Waldhausen (Chair); G. Bernard; D. DeMets; M. Ferguson; E. Hoover; R. Levine; D. Mahler; A.J. McSweeny; J. Wiener-Kronish; O.D. Williams; M. Younes.

Marketing Center, Temple University, Philadelphia, PA, USA: G. Criner (Principal Investigator); C. Soltoff.

Project Office, National Heart, Lung, and Blood Institute, Bethesda, MD, USA: G. Weinmann (Project Officer); J. Deshler (Contracting Officer); D. Follmann; J. Kiley; M. Wu (19962001).

The authors would like to thank A. Gelb (Lakewood Regional Medical Center, Lakewood, CA, USA).

\section{REFERENCES}

1 Oswald-Mammosser M, Weitzenblum E, Quoix E, et al. Prognostic factors in COPD patients receiving long-term oxygen therapy. Importance of pulmonary artery pressure. Chest 1995; 107: 1193-1198.

2 Kessler R, Faller M, Weitzenblum E, et al. "Natural history" of pulmonary hypertension in a series of 131 patients with chronic obstructive lung disease. Am J Respir Crit Care Med 2001; 164: 219-224.

3 Kessler R, Faller M, Fourgaut G, Mennecier B, Weitzenblum E. Predictive factors of hospitalization for acute exacerbation in a series of 64 patients with chronic obstructive pulmonary disease. Am J Respir Crit Care Med 1999; 159: 158-164. 
4 Vonbank K, Ziesche R, Higenbottam TW, et al. Controlled prospective randomised trial on the effects on pulmonary haemodynamics of the ambulatory long term use of nitric oxide and oxygen in patients with severe COPD. Thorax 2003; 58: 289-293.

5 Higenbottam T. Pulmonary hypertension and chronic obstructive pulmonary disease: a case for treatment. Proc Am Thorac Soc 2005; 2: 12-19.

6 The National Emphysema Treatment Trail Group, Rationale and design of the National Emphysema Treatment Trial: a prospective randomized trial of lung volume reduction surgery. The National Emphysema Treatment Trial Research Group. Chest 1999; 116: 17501761.

7 Currie PJ, Seward JB, Chan KL, et al. Continuous wave Doppler determination of right ventricular pressure: a simultaneous Doppler-catheterization study in 127 patients. J Am Coll Cardiol 1985; 6: 750-756.

8 Berger M, Haimowitz A, Van Tosh A, Berdoff RL, Goldberg E. Quantitative assessment of pulmonary hypertension in patients with tricuspid regurgitation using continuous wave Doppler ultrasound. J Am Coll Cardiol 1985; 6: 359-365.

9 Tramarin R, Torbicki A, Marchandise B, Laaban JP, Morpurgo M. Doppler echocardiographic evaluation of pulmonary artery pressure in chronic obstructive pulmonary disease. A European multicentre study. Working Group on Noninvasive Evaluation of Pulmonary Artery Pressure. European Office of the World Health Organization, Copenhagen. Eur Heart J 1991; 12: 103-111.

10 Fisher MR, Hassoun PM, Criner G, Scharf S, Fessler HE. Accuracy of Doppler echocardiography for pulmonary hypertension in the National Emphysema Treatment Trial. Am J Respir Crit Care Med 2004; 169: A178.

11 Scharf SM, Iqbal M, Keller C, Criner G, Lee S, Fessler HE. Hemodynamic characterization of patients with severe emphysema. Am J Respir Crit Care Med 2002; 166: 314-322.
12 Centers for Medicare and Medicaid Services. Decision Memo for Home Use of Oxygen. CMMS Publication CAG00296N. US Government Printing Office, Washington DC, 2006.

13 Bland JM, Altman DG. Statistical methods for assessing agreement between two methods of clinical measurement. Lancet 1986; 1: 307-310.

14 Simonneau G, Galie N, Rubin LJ, et al. Clinical classification of pulmonary hypertension. J Am Coll Cardiol 2004; 43: Suppl. 12, 5S-12S.

15 McGoon M, Gutterman D, Steen V, et al. Screening, early detection, and diagnosis of pulmonary arterial hypertension: ACCP evidence-based clinical practice guidelines. Chest 2004; 126: Suppl. 1, 14S-34S.

16 Arcasoy SM, Christie JD, Ferrari VA, et al. Echocardiographic assessment of pulmonary hypertension in patients with advanced lung disease. Am J Respir Crit Care Med 2003; 167: 735-740.

17 Bach DS, Curtis JL, Christensen PJ, et al. Preoperative echocardiographic evaluation of patients referred for lung volume reduction surgery. Chest 1998; 114: 972-980.

18 Laaban JP, Diebold B, Zelinski R, Lafay M, Raffoul H, Rochemaure J. Noninvasive estimation of systolic pulmonary-artery pressure using Doppler echocardiography in patients with chronic obstructive pulmonary disease. Chest 1989; 96: 1258-1262.

19 Torres F, Tye T, Gibbons R, Puryear J, Popp RL. Echocardiographic contrast increases the yield for right ventricular pressure measurement by Doppler echocardiography. J Am Soc Echocardiogr 1989; 2: 419-424.

20 Beard JT, Byrd BF III. Saline contrast enhancement of trivial Doppler tricuspid regurgitation signals for estimating pulmonary artery pressure. Am J Cardiol 1988; 62: 486-488.

21 Himelman RB, Stulbarg MS, Lee E, Kuecherer HF, Schiller NB. Noninvasive evaluation of pulmonary artery systolic pressures during dynamic exercise by salineenhanced Doppler echocardiography. Am Heart J 1990; 119: 685-688. 